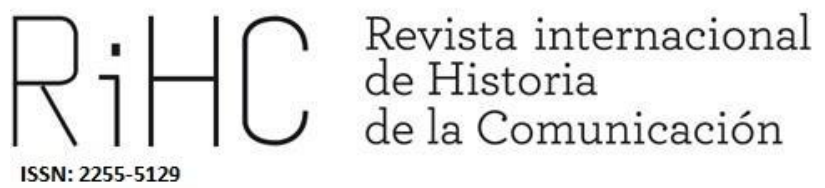

\title{
LA GUERRA DE IFNI, ECOS AMORDAZADOS Y HUELLAS DISIPADAS POR LA PRENSA DEL FRANQUISMO
}

The Ifni War, muzzled echoes and fading footprints as a result of the Francoism press

DOI: https://dx.doi.org/10.12795/RiHC.2020.i15.11

Recibido: 01-09-2020

Aceptado: 08-12-2020

Publicado: $30-12-2020$

Mónica Yanguas Muñoz

ORCID (D) 0000-0001-7554-9274

Universidad Carlos III de Madrid

monica.yanguas1@gmail.com

Como citar este artículo: YANGUAS MUÑOZ, Mónica (2020): “La Guerra de Ifni, ecos amordazados y huellas disipadas por la prensa del franquismo", en Revista Internacional de Historia de la Comunicación, (15), pp. 212-241. 
Resumen: Este trabajo de investigación se centra en un análisis de la prensa española coetánea a la Guerra de Ifni, estudiada de forma comparativa con los sucesos y testimonios de quienes vivieron esta experiencia bélica y aquellos que presentan una relación profesional con ella (en concreto, un periodista). Se trata de un conflicto enmarcado en la dictadura franquista y el proceso de descolonización y expansión de Marruecos en los años centrales del siglo XX.

El objetivo general que planteamos es comprobar la manipulación de los medios de comunicación en la guerra, concretamente de la prensa, y paralelamente contribuir a desenterrar a Ifni del olvido. El artículo pone de manifiesto la historia de Ifni en relación con España, los mecanismos franquistas de control informativo y algunos resultados de la contienda en la actualidad.

Palabras clave: Guerra de Ifni, prensa, franquismo, colonialismo.

\begin{abstract}
This research focuses on the analysis of Spanish press which chronologically concurs with the Ifni War, studied contrasting the events and testimonies of those who experienced this war and those who entail a professional relationship with it (a journalist specifically). It was a conflict in the framework of the Francoist dictatorship and the process of decolonisation and expansion of Morocco in the mid-twentieth century.

The general aim that we consider is to verify the interference of the media during the war, specifically press, and simultaneously contribute to unearth Ifni from the abyss of oblivion. This article brings to light the history of Ifni in relation to Spain, the Francoist mechanisms of informative control and some of the current outcomes of the war.

Keywords: Ifni War, press, Francoism, colonialism.
\end{abstract}

\title{
Introducción y metodología
}

La Guerra de Ifni (1957-1958) fue la última contienda colonial librada por España en el norte de África. Censurada por el régimen franquista, ha caído en el olvido, o al menos no se ha recordado lo suficiente. Tan es así que muchos historiadores la han calificado de guerra ignorada u olvidada.

De acuerdo con Vidal Guardiola (2006: 10): “(...) da lástima que nadie recuerde aquel capítulo de la historia, triste y chapucero, si se quiere, pero que sucedió. (...) España hizo tal ridículo en aquella guerra que era lógico que se ocultase a la opinión pública". No se planteó como una guerra abierta "Marruecos contra España", sino como una invasión de las guerrillas del llamado Ejército de Liberación. En teoría y de manera oficial, estas bandas estaban desvinculadas del gobierno de Rabat, pero, en la praxis, no fue así. 
La Guerra de Ifni constituye un ejemplo muy interesante para analizar la manipulación de los hechos que puede realizar el periodismo, la cual se basó en varias estrategias que examinaremos en este artículo: el ocultamiento de la información; la propaganda; la manipulación del lenguaje, con la selección de términos para la construcción de realidades, al menos en el imaginario colectivo; la culpabilización a un enemigo externo, en este caso el comunismo, y, por último, la manipulación histórica.

Esta investigación plantea como objetivo comprobar la importancia del papel de los medios de comunicación en un conflicto, como es la Guerra de Ifni, en un marco de censura, estricto control y propaganda. De manera subsidiaria busca desenterrar del olvido la Guerra de Ifni. Se trata de un conflicto insuficientemente conocido, pese a que murieron aproximadamente trescientos soldados españoles y hubo más de medio centenar de heridos en el Ejército español (Vidal Guardiola, 2006: 10), además de ochenta desaparecidos y cuarenta prisioneros, mientras que se desconocen las cifras de bajas y muertes dentro del Ejército de Liberación (Bárbulo, El País, 18-11-2007, p. 1).

Hemos delimitado como objeto de estudio la prensa española, tanto generalista como especializada de los años 1957 y 1958. No obstante, también se abordará prensa de años anteriores y posteriores, ya que algunos historiadores y ciertos entrevistados consideran que el conflicto se inició anteriormente, en 1956, e incluso antes (Bosque Coma, 2007: 38-44), y no se puede dar por finalizado hasta el 30 de junio de 1969, cuando se entregó Sidi Ifni a Marruecos.

La metodología utilizada es de carácter cualitativo. Por un lado, se ha aplicado la técnica del análisis de contenido cualitativo de cuatro periódicos y una revista especializada: $A B C$, Informaciones, La Vanguardia, Ya y A.O.E. Revista Ilustrada del África Occidental Española. Se han escogido por su repercusión y tirada, en el último caso por su popularidad en Ifni y por ser un ejemplo de prensa local ${ }^{1}$. Con ellos se ha procedido a la detección del medio, el autor, el título y un breve resumen del contenido, y se ha ordenado cronológicamente (véase Anexo).

No se ha considerado oportuno analizar más prensa, ni tampoco examinarla cuantitativamente, puesto que, al fin y al cabo, la información estaba muy monopolizada por el Estado, a partir de la Agencia Efe. De hecho, tras analizar toda la información, se ha comprobado lo ya mencionado. Se ha optado por seleccionar ejemplos de prensa generalista $(A B C$, La Vanguardia, Informaciones y $Y a$ ), así como muestras de prensa especializada (A.O.E. Revista llustrada del África Occidental Española).

\footnotetext{
${ }^{1}$ A.O.E. era una publicación semanaria (1945-1968) que surgió dentro del Grupo de Tiradores de Ifni (Pérez García, 2006: 191).
} 
Hemos elegido las obras periodísticas de $A B C$ y $L a$ Vanguardia por razones prácticas, ya que las consultas están facilitadas por sus hemerotecas digitales, aunque la búsqueda realizada va más allá de esto: para el estudio de las piezas periodísticas de Informaciones y $Y a$, se han consultado los ejemplares microfilmados que se encuentran en la BNE, Biblioteca Nacional de España. Además, para el análisis de A.O.E. Revista llustrada del África Occidental Española, se han hecho consultas a través del buscador de revistas de la ULPGC, Universidad de las Palmas de Gran Canaria.

Por otro lado, hemos aplicado la técnica de la entrevista en profundidad a cinco personas seleccionadas que vivieron la Guerra de Ifni o tienen alguna relación personal y/o profesional con la misma. Sus testimonios son interesantes pues permiten comparar sus realidades y experiencias con la información original que aparecía en la prensa, basada en el silenciamiento de los sucesos bélicos.

Alfonso Carlos Alsúa, entrevistado el 07-10-2019, nació en Pamplona en 1935; fue miembro de la Policía Territorial de Ifni, hecho prisionero en el puesto de Tabelcut, en la antigua frontera entre Ifni y Marruecos. Desde el 26 de noviembre de 1957, en plena guerra, pasó año y medio secuestrado en manos de los marroquíes, junto con otros treinta y nueve prisioneros españoles.

Luis Ruiz Gutiérrez, entrevistado el 16-10-2019, nació en Tánger en 1941, y sirvió en el Grupo de Tiradores no 1 de Ifni, como soldado de quinta, bajo el servicio militar obligatorio, entre 1963 y 1964 . Ha trabajado como historiador en la Universidad de Arizona y ha sido presidente de la Asociación de Amigos de Ifni ${ }^{2}$, con sede en Madrid, durante los años 2015-2019.

María Teresa Suárez Lorenzo, entrevistada el 30-10-2019, nació en 1947 en Tagragra, un pequeño pueblo de Ifni, vivió la guerra en su niñez y parte de su vida en Ifni. Cuando se produjo la retrocesión de Sidi Ifni (1969), tuvo que partir.

Pablo Ignacio de Dalmases y Olabarría, entrevistado el 14-11-2019, nació en 1946, es doctor en Historia, con una tesis sobre el Sáhara español, cuestión a la que ha dedicado numerosos libros. Se licenció en Periodismo, Publicidad y Relaciones Públicas; trabajó en Solidaridad Nacional y La Prensa, periódicos del Movimiento; fue director de Radio Sáhara y del periódico La realidad, editado en El Aaiún (Sáhara) en 1975, y ha trabajado como redactor en Radio Nacional Española durante treinta y tres años. Este testimonio es quizá uno de los más pertinentes, por su labor como periodista. No se han recogido

\footnotetext{
2 Esta asociación, compuesta por 286 miembros, busca la difusión y divulgación de información sobre Ifni a través de distintas actividades, como reuniones, conferencias o viajes.
} 
más testimonios de este estilo, por una cuestión cronológica (muchos de los periodistas que trabajaron en las décadas cincuenta y sesenta del siglo pasado ya han fallecido).

Pablo Vázquez Ramírez, entrevistado el 2-11-2019, nació en Sidi Ifni en 1960, descendiente de españoles, y pasó allí parte de su niñez (1960-1969). Su padre fue maestro herrador en el Grupo de Tiradores no 1 de Ifni. Actualmente, es ingeniero industrial, doctor en Tecnologías de la Información, y trabaja en la Universidad de Las Palmas de Gran Canaria. Es socio de honor en AVILE, Asociación de Veteranos de Ifni del Levante Español, y gestor de la página web El Rincón de Sidi Ifni, relevante por su labor divulgativa.

Partimos de las siguientes hipótesis: como es sabido, los medios de comunicación en la dictadura estaban sujetos a censura y un férreo control, hecho que repercutió, entre otros, en que la Guerra de Ifni cayera en el olvido de manera intencionada a fin de no revelar a la sociedad española ningún tipo de tensión ni conflicto. La propaganda del Régimen de Franco respecto a la paz social que se vivía era incompatible con la narración periodística de ningún enfrentamiento bélico, mucho menos con Marruecos, presentado a la opinión pública como un "país hermano". Dicho conflicto revela la importancia de la elección de las palabras, que no son casuales en periodismo, y que contribuyen a la construcción de realidades, al menos en el imaginario colectivo.

Como se puede observar, acorde con muchos historiadores, existe una "tergiversación de la memoria del franquismo" (Molinero Ruiz, 2002: 98). Nos podemos acoger, como Pizarroso Quintero, a la definición de propaganda que ofrece Edwards como expresión de una opinión orientada de manera intencionada a influir en las opiniones o actos de ciertos individuos con fines concretos (Pizarroso Quintero, 1990: 28).

\section{Estado de la cuestión}

Cuando tuvo lugar el enfrentamiento bélico, los medios de comunicación cubrieron el conflicto sin apodarlo como "guerra". Los archivos militares no dieron facilidades de acceso y las primeras obras sobre la Guerra de Ifni surgieron ya en los años 1970-1980, sobre todo tras la muerte de Franco en 1975. Estas primeras monografías estaban firmadas por Ramiro Santamaría Quesada (1984) y Rafael Casas de la Vega (1985), afines al régimen franquista.

Como tales, muestran algunas ideas próximas a la versión oficial del régimen y de la prensa. Por ejemplo, en la obra póstuma Ifni-Sáhara. La guerra ignorada (1984) del periodista Ramiro Santamaría hallamos apelaciones al heroísmo o la culpabilización del 
comunismo (Santamaría Quesada, 1984: 25-41), aunque también responsabiliza a Marruecos (Santamaría Quesada, 1984: 60-91).

Todo este panorama se complementa con expertos en las antiguas colonias españolas en África. Uno de los primeros historiadores en tratar la cuestión fue Víctor Morales Lezcano, cuyas investigaciones se han centrado en Marruecos. Asimismo, son de destacar las aportaciones de María Rosa de Madariaga, aunque quizás su interés venga dado por la vinculación de su obra y de la zona con el franquismo.

Desde comienzos del siglo XXI se han publicado libros de testimonios y en la actualidad existe una bibliografía variada en España, no solo elaborada por historiadores, como se ve, por ejemplo, en las obras de Vidal Guardiola o Gastón Segura. Sin embargo, tampoco debemos dejar de lado algunas limitaciones o dificultades, que siguen existiendo hoy en día: la falta de acceso a documentación extranjera, por ejemplo, marroquí, y la restricción a ciertos archivos históricos, como consecuencia de la Ley de Secretos Oficiales de 1968.

\section{Contexto histórico general}

\subsection{Recorrido histórico y antecedentes a la guerra}

Ifni es un territorio que pertenecía a España, situado en la actual costa marroquí, al norte del Sáhara. Se trata de una zona pesquera cuyo origen se remonta a la conquista de los Reyes Católicos, cuando Diego García de Herrera estableció en 1476 una fortaleza en Santa Cruz de la Mar Pequeña. En 1524, algunas poblaciones locales asaltaron el territorio.

Las mayores negociaciones para recuperar la antigua plaza tendrían lugar en el siglo XIX, cuando se produjo una interpretación errónea respecto a su localización o "falsa reconstrucción histórica" (Pérez García, 2003: 212). En realidad, el enclave se ubicaba en Puerto Cansado, no en la actual zona de Ifni, servía como puerta comercial y permitía incursiones en el Sáhara para la búsqueda de esclavos y su posterior envío a las plantaciones de Canarias (Pérez García, 2003: 212).

El origen de la confusión reside en el Tratado de Paz y Amistad entre España, bajo la monarquía de Isabel II, y Marruecos, bajo el reinado de Mohamed IV, tras la llamada Guerra de África (1859-1860) (Pérez García, 2003: 214-215). El acuerdo se produjo tras 
la Batalla de Wad-Ras, que finalizó con la victoria española. Todo ello se enmarca en un panorama más amplio de colonialismos europeos que culminaría con la Conferencia de Berlín (1884-1885), la cual sentaría las bases para un reparto de África (Madariaga, 2013: 23-69).

El tratado otorgaba a España derechos sobre una pesquería para una posterior ocupación en Santa Cruz de la Mar Pequeña. La cuestión de su ubicación originó debate entre geógrafos. En 1878, viajó una comisión a la costa africana que concluyó con dos posturas enfrentadas: Fernández Duro situaba Santa Cruz de la Mar Pequeña en Ifni, mientras que Alcalá Galiano lo emplazaba cerca de Puerto Cansado (Pérez García, 2003: 215-216).

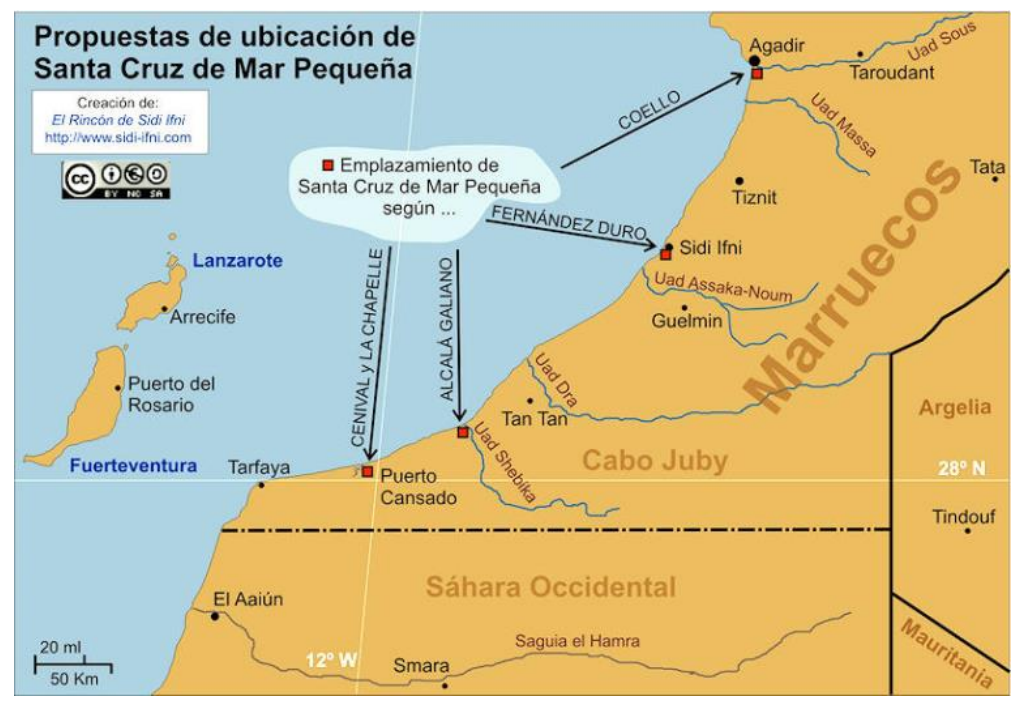

Ilustración 1. Posibles emplazamientos de Santa Cruz de Mar Pequeña según geógrafos e historiadores. Fuente: El Rincón de Sidi Ifni.

Como explica Madariaga, en el contexto de colonialismos mencionado, se establece un tratado hispanofrancés en 1912, por el cual Francia, sin permiso del sultán, cedía la zona sur marroquí a España (Madariaga, 2013: 71-113). En el norte, los rifeños iniciaron sus protestas contra la ocupación colonial en la llamada Guerra del Rif (1920-1926), en la que participó el famoso líder Abd el-Krim.

La ocupación efectiva de Ifni no tuvo lugar hasta 1934, en plena Segunda República española, cuando fue liderada por el coronel Osvaldo Capaz. Tras la ocupación, empezaron a destinar a muchos militares españoles allí, como al padre de una de las entrevistadas (María Teresa Suárez Lorenzo en entrevista telefónica con la autora, 2019). Ifni también se erigía como una posibilidad de prosperar para españoles civiles, como sucedió con la familia materna de Pablo Vázquez Ramírez, originaria de Mojácar. Su abuelo se convirtió en el primer taxista y conductor de autocares del nuevo territorio colonial, ya que, tras la ocupación, se incorporó un nuevo trayecto (Tetuán-Ifni) a la línea 
de autocares, cuyo propietario se apellidaba Bernal, al ya existente (Melilla-Tetuán). Todo ello fue fruto del establecimiento de infraestructuras occidentales (Pablo Vázquez Ramírez en entrevista digital con la autora, 2019).

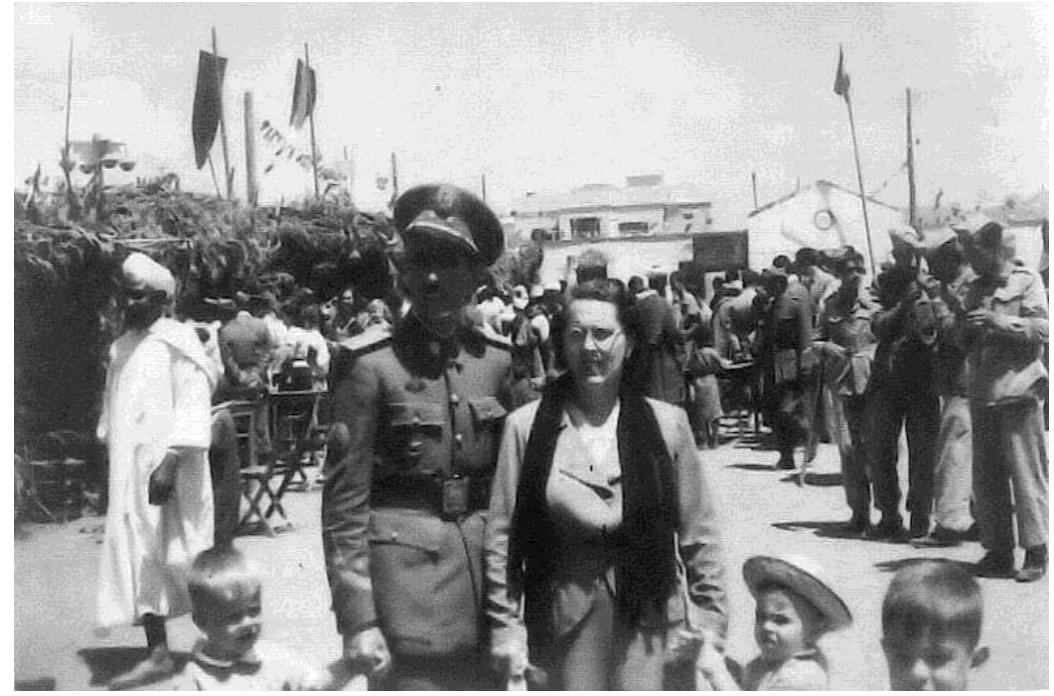

Ilustración 2. Fiestas del "6 de abril" (fundacionales) del año 1952. Fuente: archivo personal de Pablo Vázquez Ramírez.

Con el golpe de estado de 1936, la zona cayó en manos de los sublevados (Vidal Guardiola, 2006: 17-20). En los años cuarenta, la presencia española no solo se ubicaba en Ifni, sino en África Occidental (protectorado español en Marruecos, Ifni y Sáhara) y en África Ecuatorial (Fernando Poo y Guinea), dos realidades distintas.

En 1956, Franco se vio obligado a conceder la independencia de una parte del actual Marruecos, pero no cedió otras zonas que consideró españolas desde la Edad Moderna (Ceuta, Melilla, Sáhara occidental, Cabo Juby, incluido Tarfaya, e Ifni). Sin embargo, para Marruecos, no fue suficiente e inició un proyecto expansionista, sobre todo fomentado por líderes del Istiqlal ${ }^{3}$, como Allal al-Fassi (Ilamado simplemente "el Fassi" en la prensa española). En 1957, sectores del Ejército de Liberación, fundado en 1955, liderado por Ben Hammu y formado por guerrillas marroquíes, entre las que se situaban partes del Istiqlal, atacaron Ifni.

\footnotetext{
${ }^{3}$ Istiqlal es un partido fundado en Rabat en 1943 que defendía la independencia de Marruecos. Luis Ruiz Gutiérrez lo define como "el partido que apoyó al rey sin ser monárquico [para lograr la independencia de Marruecos]" (Luis Ruiz Gutiérrez en entrevista con la autora, Madrid, 2019).
} 


\subsection{Intereses de España}

La guerra plantea una cuestión: qué intereses tenía España y qué valor presentaba esta región. En 1958, la población ifneña estaba compuesta por casi 52.000 habitantes, de los cuales 47.000 eran nativos, y el resto, de origen europeo (Pérez García, 2003: 210). Esta población nativa, baamaraní, procedía de los llamados "bereberes falsos"4; se regía por leyes cheránicas y contaba con administraciones propias que quedaron supeditadas a las españolas.

Respecto a su topografía, Ifni se encuentra rodeado de montañas, lo que hace que quede aislado, en la costa. En los años cincuenta, su mayor fuente de riqueza era la pesca. No obstante, la explotación pesquera no parecía ser una tarea sencilla, puesto que Ifni cuenta con costas peligrosas. La construcción del puerto con teleférico en Sidi Ifni, la antigua capital, en los sesenta, facilitó la industria pesquera, pero su edificación fue una tarea muy costosa para el régimen franquista, lo cual se reflejó en la prensa ("El presupuesto de la provincia de Ifni", $A B C$ (Madrid), 11-5-1966, p. 82).

Aunque es cierto que las colonias se llegaron a convertir en el "espacio vital" de la autarquía (Suárez Blanco, 1997: 322), Ifni no parecía ser el grueso de las regiones españolas en África. Por el contrario, Sáhara contaba con yacimientos de fosfato, que se descubrieron en la década de los sesenta, y Guinea, con diversas materias primas: café, cacao, madera y material para fabricar caucho.

Marruecos era la mayor prioridad hasta 1956, puesto que ofrecía un nuevo mercado y respondía también a intereses militares, de prestigio y factores sentimentales. Sin duda, el franquismo tenía su origen aquí (Suárez Blanco, 1997: 316-317).

En suma, Ifni contaba con un banco pesquero y una buena ubicación, pero no era tan valorado como otros territorios. Por consiguiente, los intereses españoles en la zona no eran tanto económicos, sino pertenecientes al ámbito de la política colonial.

\footnotetext{
${ }^{4}$ Pérez García recurre a Fernández-Aceytuno para explicar este concepto: los "bereberes falsos" son el resultado de mezclas de población bereber y árabe (Pérez García, 2003: 210).
} 


\section{Análisis de la cobertura informativa}

\subsection{Breve nota sobre el marco jurídico periodístico}

El Ministerio de Información y Turismo fue creado en 1952. En esta época, todavía estaba en vigor la denominada "ley Serrano Súñer", promulgada en 1938, la cual establecía la censura previa y la elaboración de consignas a los periodistas, bajo el concepto, entre otros, de periodismo como instrumento al servicio del Estado (Eiroa y Carrera, 2008: 20-23).

La ley no sería sustituida hasta 1966, con la apodada "ley Fraga", en honor a su promotor, el ministro Manuel Fraga. En esta época, Dalmases, uno de los entrevistados, ya había pasado por la Escuela de Periodismo ${ }^{5}$, trabajaba en La Prensa y recuerda que el director de este periódico del Movimiento, Domínguez Isla, organizó una cena para celebrar la nueva ley, que suponía una cierta apertura:

Era una nueva etapa en la que se establecía una teórica libertad de prensa, aunque también unas limitaciones, sobre todo en el Artículo 2: el respeto a la ley y la verdad, la moral católica, los principios y leyes del Movimiento, etc. Se suprimía la censura, pero, ojo, se creaba un sistema un poco diabólico, (...) si tú querías escribir un texto un poco delicado o arriesgado podías hacerlo con el riesgo de confiscación, pero también podías cubrirte la espalda con la consulta previa (...).

Dentro de los mecanismos [de control informativo] hay muchos directos e indirectos. Directos: la censura, la fuerza de la autoridad, pero también indirectos [como ahora]: la publicidad, las llamadas telefónicas o las presiones de «no publiques esto, esto no conviene» (Pablo-Ignacio de Dalmases en entrevista telefónica con la autora, 2019).

La vigilancia y control de la prensa y de los profesionales fueron intensos durante todo el franquismo (Reig Cruañes, 1995: 123-134). Incluso el mismo Dalmases fue amenazado en el año 1975 cuando pasó a ser director de La Realidad, periódico bilingüe, en hassaní y castellano, editado en El Aaiún (Sáhara): "Me quedé colgado de la copa de una palmera. Un grupo de militares ultras (...) de la Policía Territorial me detuvieron [sic] [detuvo] ilegalmente una noche y unos días después me dijeron que o me largaba o me pegaban unos tiros" (Pablo-Ignacio de Dalmases en entrevista telefónica con la autora,

\footnotetext{
${ }^{5}$ Entonces solo existían tres escuelas para la formación de periodistas: la Escuela Oficial, en Madrid; la Escuela de la Iglesia, y el Instituto del Opus Dei, en Pamplona (Pablo-Ignacio de Dalmases en entrevista telefónica con la autora, 2019).
} 
2019). Esto fue debido a la publicación de una noticia en primera plana que anunciaba que España y Marruecos llegarían a un acuerdo en la cuestión saharaui.

El control de la información sobre Ifni, incluso hasta 1969, se basó en varias estrategias, que se examinan en los apartados siguientes.

\subsection{El ocultamiento de la información}

Se considera que la guerra se inició el 23 de noviembre de 1957, pero en realidad, como ya se ha mencionado, los ataques y atentados, con heridos y muertos, ya habían empezado con anterioridad. Así lo demuestra el testimonio de Alfonso Carlos Alsúa: “(...) estábamos en guerra todo el tiempo (...). Teníamos que dormir en el cuartel con la ropa puesta, esperando un ataque en cualquier momento. (...) El mando de Sidi Ifni [la capital] ordenó hacer un escudo alrededor, y los que estábamos fuera nos quedamos a nuestra suerte: era morir o caer prisioneros" (Alfonso Carlos Alsúa en entrevista telefónica con la autora, 2019).

No obstante, los ataques anteriores apenas aparecían en la prensa española, que se centraba en la "ejemplar" acción de las fuerzas armadas. $A B C$, en concreto, mencionaba en 1950 “(...) el esfuerzo, el amor y la voluntad constructiva de los militares españoles en Ifni" ("Memorias del Ayuntamiento de la ciudad de Ifni", $A B C$ (Madrid), 1-12-1950, p. 16), y en la misma línea se situaba La Vanguardia ("El año africano", La Vanguardia, 11-1953, p. 3).

Todo este ambiente de amor y buenismo choca con el ataque del 23 de noviembre, día en el que se inició una guerra más bien defensiva para el Ejército español. Alsúa sostiene que el armamento marroquí era de fabricación francesa y española, y describe así la guarnición que estaba a su disposición: "Era un armamento obsoleto, de la guerra española [la Guerra Civil (1936-1939)] ${ }^{6}$, que casi ni disparaba. (...) Aquello fue un desastre. En un terreno que era pedregoso, íbamos con alpargatas (...)" (Alfonso Carlos Alsúa en entrevista telefónica con la autora, 2019).

Los hechos sucedieron el 23 de noviembre de 1957, pero no se informó hasta el día 27. El 27 de noviembre, la prensa generalista ( $A B C$, Informaciones, La Vanguardia y $Y a$ ) publicaba una "Nota del Ministerio del Ejército", con el objetivo de "tener debidamente informada a la opinión pública" ("Nota del Ministerio del Ejército", $A B C$ (Madrid), 27-111957, p. 31). En la mayoría de los casos, la nota aparecía en portada, aunque no hay ningún tipo de información al respecto en A.O.E., pese a que este era un medio que se

\footnotetext{
${ }^{6}$ Las armas que se usaron también procedían de la Segunda Guerra Mundial (1939-1945), pues España no contaba con una industria armamentística, ni propia ni externa.
} 
editaba en Ifni y podía obtener la información de primera mano. Es más, en noviembre y diciembre, punto álgido del enfrentamiento bélico, apenas encontramos noticias sobre la guerra en esta revista. Estas empiezan a publicarse en enero de 1958 y solo hacen alusión al heroísmo. Las noticias de A.O.E. estaban más bien ligadas al día a día ("La vida en los territorios de la A.O.E.", A.O.E. Revista ilustrada del África Occidental Española, 03-11-1957, p. 7).

En el resto de prensa, la nota apuntaba a “(...) bandas armadas del llamado Ejército de Liberación que por todos los medios vienen intentando perturbar la paz y el orden entre los indígenas (...)". Con ello también se daba a entender que la población autóctona apoyaba a las autoridades españolas. Además, aunque es cierto que en la nota no se niega el ataque, se describe como una victoria de las tropas españolas: "El espíritu de los mandos y tropas de los tres Ejércitos es excelente".

Al día siguiente, apareció en los periódicos una nota procedente de la Agencia Efe titulada "La situación en las zonas próximas a Sidi-Ifni", en la que se negaban las afirmaciones de los medios extranjeros y se hablaba de normalidad ("La situación en las zonas próximas a Sidi-Ifni", La Vanguardia, 28-11-1957, p. 4) 7.

En los días 29 y 30 de noviembre de 1957, tuvieron lugar las primeras operaciones militares, como la de Netol, que supusieron la liberación de algunos puestos, como Tiliuín o Tzelata. El día 29 se publicó otra nota emitida por el Ministerio del Ejército ("Nota del Ministerio del Ejército", $A B C$ (Madrid), 29-11-1957, p. 31). Aunque quizá $A B C$ use un tono más efusivo, la textualidad se mantenía, únicamente variaba el titular. Se informaba de la "felicitación del Generalísimo a las guarniciones de Ifni y Sáhara" y se indicaba que la situación evolucionaba favorablemente, a pesar de que el dominio español quedaría reducido a Sidi Ifni, la capital.

\footnotetext{
${ }^{7}$ El titular variaba según el medio, pero la información era literalmente la misma. Una diferencia mínima consistía en que Ya incluía un pequeño mapa con la ubicación de Ifni.
} 

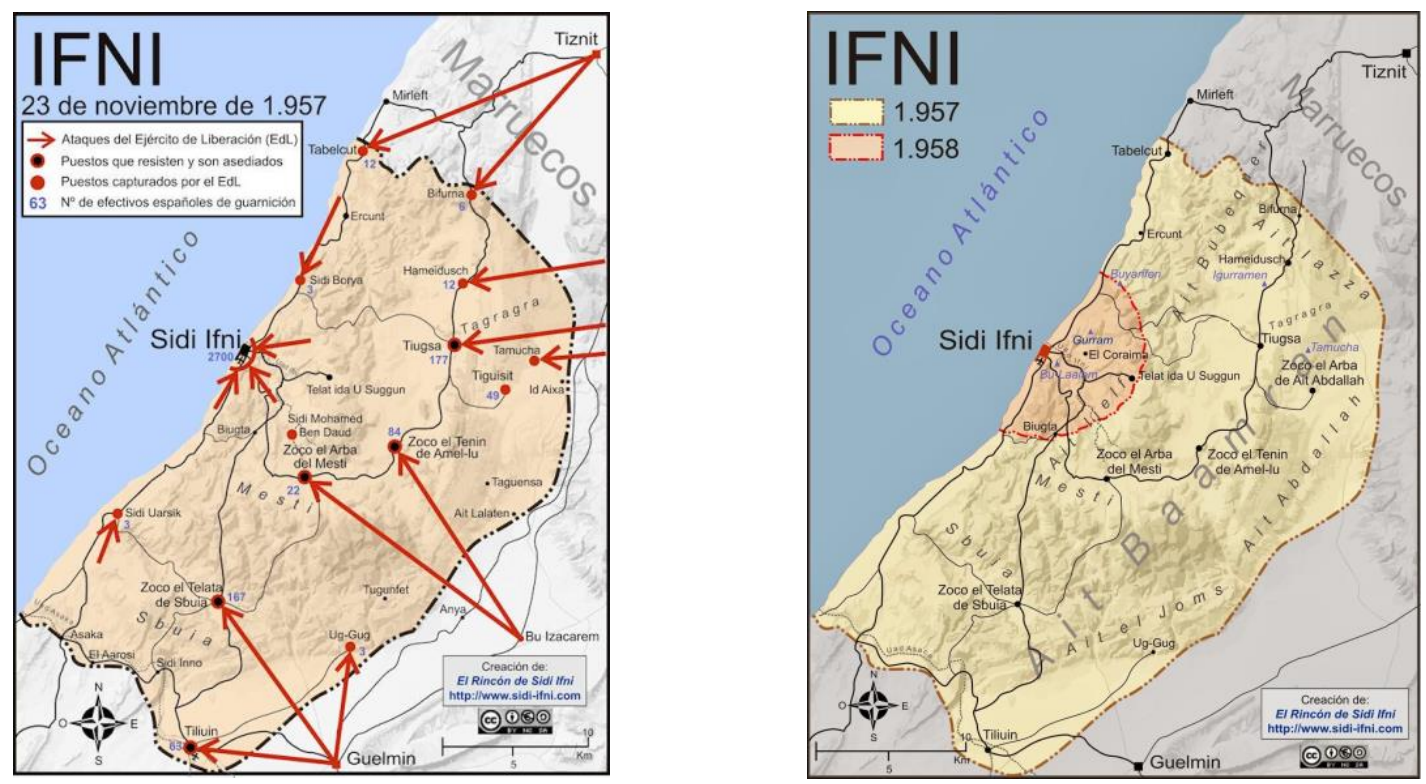

Ilustraciones 3 y 4. Ataque al territorio de Ifni el 23 de noviembre de 1957 y el dominio español en los años 1957-1958. Fuente: El Rincón de Sidi Ifni.

De nuevo, todo ello puede ser cuestionado a partir de los mapas (llustraciones 3 y 4 ) y los testimonios de las personas que vivieron la experiencia bélica. Suárez Lorenzo, una de las niñas de la guerra, recuerda así los ataques del Ejército de Liberación de noviembre de 1957 en Tagragra:

Mis padres eran canarios. Mi padre era militar y estuvo destinado en Ifni. Allí nació mi hermana, mis dos hermanos y yo. Yo era la más pequeña y nací en Tagragra, un pueblecito. Allí pasé mi niñez hasta 1957, cuando nos pilló la guerra. (...) Éramos catorce niños allí [¿¿y un bebé?]. Mi hermana era la mayor, que tenía 15 años, y el más pequeño era un bebé, que tenía dos meses, y a su madre la habían matado. Mi madre se hizo cargo de él, [quien] hoy ya tiene 62 años.

Mi madre se hizo cargo de los quince niños. A nosotros decidieron meternos en un pozo, para estar más resguardados de las balas, y a mi madre la sacaban por la mañana para que hiciera la comida para todos nosotros y para los soldados. También ayudaba en el botiquín a cuidar a los soldados y militares heridos. Mi madre fue una heroína, y no es que lo diga yo: han escrito muchos libros sobre la guerra de Ifni y el Sáhara, y mi madre aparece como una heroína (...).

Allí nosotros ayudábamos a rellenar los sacos de arena para hacer trincheras, para que no entraran las balas, pero llegó un punto en que entraban por todos los lados, por lo que decidieron meternos en el pozo (María Teresa Suárez Lorenzo en entrevista telefónica con la autora, 2019). 
Mientras tanto, Alsúa vivió los ataques en Tabelcut. Es muy difícil corroborar las cifras, pero el entrevistado habla de unos doscientos atacantes frente a un puesto de nueve militares y cuatro civiles españoles:

En mi puesto fue bastante duro. (...) Aguantamos hasta el día 27, y el 28 ya no atacaron, sino que apareció un caíd de Tiznit, según decían, con una bandera blanca. El teniente Felipe Sotos y el cabo de la Guardia Civil hablaron con él y decidieron que nos iban a entregar al cónsul de Agadir, aunque nosotros, los soldados, no queríamos, porque teníamos miedo. Pensábamos que nos iban a matar (Alfonso Carlos Alsúa en entrevista telefónica con la autora, 2019).

Este grupo de españoles fue trasladado a Mirleft, donde fueron atados y secuestrados en un autobús. Fue así como empezó un año y medio de cautiverio en pésimas condiciones y en varios puestos. En el segundo -narra Alsúa- fue consciente de la cantidad de presos españoles que había, que procedían de otras zonas. La cifra ascendía a un total de cuarenta prisioneros (treinta y dos militares, el resto civiles).

El secuestro en Cabo Bojador (Sáhara) es otro ejemplo más de la falta de información. A.O.E. no hace ninguna alusión a este hecho, mientras que en el resto de prensa analizada se publican algunas noticias el 4 de diciembre de 1957 en las que se habla de "secuestro", "asalto" y "desaparecidos" ("Ha sido liberado por las tropas españolas el importante nudo de comunicaciones de T'Zebala de Sbuia", ABC (Madrid), 4-12-1957, p. 15). No obstante, no se vuelve a dar referencias hasta agosto de 1958 y tan solo se dice que "son objeto de buen trato" ("Noticias de los desaparecidos en Ifni", ABC (Madrid), 09-08-1958, p. 23), algo que se puede refutar a partir del testimonio de Alsúa:

El cautiverio fueron [sic] [duró] siete meses. Estábamos durmiendo en el suelo, no teníamos luz, las ventanas cerradas, teníamos piojos, chinches... Teníamos de todo, y de vez en cuando nos sacaban afuera, al sol, y nos tenían allí hasta que caíamos al suelo. Nos llevaban a una habitación en la que había agua y nos ataban de tres en tres, hasta que caías, o sino nos pegaban. Nos pegaban mucho y no comíamos más que un nabo al día.

Durante este período, solo se desvelan "operaciones de limpieza" en el Sáhara español contra las bandas que habían actuado tanto en Ifni como en Sáhara ("Brillantes operaciones de limpieza en el Sáhara español", $A B C$ (Madrid), 2-03-1958, p. 63-64). En este último artículo se recoge lo siguiente:

El llamado Ejército de Liberación y quienes lo alientan vienen difundiendo desde Marruecos fantásticos partes y noticias que no es preciso refutar dadas las ridículas falsedades que habitualmente propalan les han desacreditado ante la opinión pública mundial. Una de las últimas fantasías ha sido la de afirmar que 
franceses y españoles han utilizado gases asfixiantes, con los que aniquilaron a un grupo de 600 personas. Es este un infundio más que confirma la sorprendente semejanza de su propaganda con los procedimientos empleados por la técnica comunista, caracterizada por su falta absoluta de respeto a la verdad. Este Ministerio lamenta profundamente que en Marruecos se tolere la propagación de tales falsedades ("Brillantes operaciones de limpieza en el Sáhara español", $A B C$ (Madrid), 2-03-1958, p. 63-64).

Como posible línea futura de investigación, se podría comparar esta información con la arrojada en prensa extranjera (por ejemplo, francesa, inglesa y/o marroquí). En caso de que estos datos sean ciertos, sería interesante analizar el contraste como base para demostrar más ocultaciones y manipulaciones de la prensa franquista.

Los cuarenta españoles serían liberados en mayo de 1959, más de un año después de la fecha oficial de finalización de las "operaciones", ya que no se hablaba de "guerra", en un acto presidido por el rey marroquí, Mohamed V. Tras la jornada, Alsúa fue trasladado a Pamplona, su lugar de origen, sin ningún tipo de reconocimiento.

La prensa sostenía que la liberación fue posible gracias al rey Mohamed $V$, quien aprovechó la ocasión para resaltar la buena amistad hispano-marroquí, a pesar de los "equívocos" anteriores (Granados, La Vanguardia, 7-5-1959, p. 3). Esta versión oficial choca con la de los testigos, como Alsúa, quien afirma: “(...) allí [en el cautiverio] había un francés, que fue el que dijo que si alguna vez salía, iría a hablar con los periodistas y diría que con él había cuarenta españoles presos" (Alfonso Carlos Alsúa en entrevista telefónica con la autora, 2019). Según Alsúa, probablemente la liberación tuvo que ver con el aviso de este francés.

Como se puede observar, el ocultamiento de la información se mantuvo. Pese a todo, de acuerdo con Vidal Guardiola: "El Régimen se vio atrapado por una gran contradicción: no podía seguir manteniendo ante la opinión pública que en África no pasaba nada y a la vez enviar contingentes numerosos de tropas a la colonia" (Vidal Guardiola, 2006: 103-104).

\subsection{La propaganda y las apelaciones al heroísmo}

Desde mediados de diciembre de 1957 se optó por dar información, pero suministrada a modo de propaganda. De este modo, se aprovecharon las navidades de 1957 y el Año Nuevo de 1958 para el envío de regalos y la visita de famosos, como el Trío las Vegas, Emma Frometa, Eider Barber, Miguel Gila o Carmen Sevilla (Mendo, La Vanguardia, 21-1958, p. 4). Igualmente, el No-Do hizo hincapié en esto (González Sáez, 2014: 73). 
Todo ello perseguía dos objetivos: elevar la moral de los soldados y mejorar la opinión pública sobre la contienda. Por tanto, no es de extrañar que también aparecieran noticias en el No-do (No-do: noticiarios y documentales, 13-1-1958) y que los diarios generalistas incluyeran fragmentos como el siguiente: “(...) comprendemos perfectamente que Carmen Sevilla haya vertido allí sus lágrimas mientras los bravos defensores de España reían y aplaudían” (“"Vengo emocionada», dijo Carmen Sevilla a su regreso de Ifni", La Vanguardia, 3-1-1958, p. 7).

Por consiguiente, el boom informativo de finales de diciembre de 1957 y principios de enero de 1958 fue más bien propagandístico. Con ello, también se incorporó una nueva estrategia comunicativa en la prensa: se apeló al heroísmo. A nivel particular, se elogió sobre todo la acción de legionarios paracaidistas, que habían sido liderados por Ortiz de Zárate, a quien se dedican varios homenajes y medallas castrenses ("En memoria del coronel Ortiz de Zárate", $A B C$ (Madrid), 25-08-1959, p. 26). También destacó la construcción de monumentos en honor al alférez Francisco Rojas de Navarrete. Sus muertes fueron tratadas como verdaderas hazañas épicas: "Su jefe, el teniente Ortiz de Zárate, había sucumbido heroicamente (...)" ("Ha sido liberado por las tropas españolas el importante nudo de comunicaciones de T'Zelata de Sbuia", ABC (Sevilla), 4-12-1957, p. 15).

Las tropas pasarían a estar lideradas por el general Gómez de Zamalloa, a quien se elogiaba a pesar de sus fracasos, e incluso se asociaba con la voluntad divina. Mientras tanto, las actuaciones del Grupo de Tiradores de Ifni aparecieron sobre todo en A.O.E. ("El Grupo de Tiradores de Ifni", A.O.E. Revista ilustrada del África Occidental Española, 19-4-1964, pp. 27-30).

El recuerdo y las laureolas de los héroes de Ifni florecieron en la prensa hasta prácticamente los años sesenta ("Confirmación de la Medalla Militar individual a tres héroes de Ifni", $A B C$ (Sevilla), 10-12-1960, p. 45). A nivel general, se resalta la heroicidad de los soldados españoles, concepto ligado al patriotismo, la hombría y al ejército. En la prensa, se percibe la repetición de términos como "valientes", "heroicos" o "magníficos" ("Cuando se festejaba el nacimiento del Señor y se velaban las armas por España", A.O.E. Revista ilustrada del África Occidental Española, 4-1-1959, p. 2).

En suma, el caso de Ifni alerta de los peligros que existen cuando se escucha la palabra "heroísmo", una reminiscencia de otros muchos episodios cruentos de la historia de Europa. Recuerda, por ejemplo, a una cita, no muy conocida, de Víctor Klemperer en La 
lengua del Tercer Reich, en referencia a la Segunda Guerra Mundial (1939-1945) y al colonialismo ${ }^{8}$.

Además, se observan nociones que podrían considerarse decimonónicas e incluso medievales, como el "caballero católico" o el sentido providencialista (Santamaría, A.O.E. Revista ilustrada del África Occidental Española, 9-2-1958, p. 3).

Lo emotivo y lo religioso se fusionan en el discurso franquista (Matese, 2014: 635). Es más, se puede hablar de un uso político de la religión e incluso de una "religión política", acompañada de sus propios ritos y mitos nacionalistas (Box, 2004: 136). Del mismo modo, existió una "imbricación entre la dictadura y la Iglesia católica" (Molinero Ruiz, 2002: 98), y hallamos “(...) la sacralización de la historia grupal (...) [y] de la entidad secular de la esfera política" (Box, 2004: 139).

Véase, por ejemplo, la repetición de términos castrenses y patrióticos, destinados a la memoria de militares (Santamaría, A.O.E. Revista ilustrada del África Occidental Española, 9-2-1958, p. 3). Como se puede observar, respecto al discurso y léxico franquista, existen numerosos estudios.

\subsection{El uso y selección de términos durante y después de la contienda, hasta 1969}

También se podría añadir, como estrategia, la utilización de las palabras para la creación de realidades. Entre los términos a examinar, hemos seleccionado: "incidentes"; "reorganización de territorios"; "moro" y "retrocesión", en vinculación con su contexto.

Dalmases matiza lo siguiente: "Ahora han salido muchos libros, uno con el título La Guerra de Ifni: la guerra que Franco silenció [(2006) del escritor Gastón Segura Valero]. Mentira, porque salió en los periódicos y en los nodos, pero lo que sí es cierto es que Franco devaluó la importancia del conflicto" (Pablo-Ignacio de Dalmases en entrevista telefónica con la autora, 2019). De un modo u otro, como ya hemos mencionado, no se

\footnotetext{
${ }^{8}$ Un día de diciembre de 1941, Paul K. volvió radiante del trabajo. Acababa de leer el parte de la guerra, camino de casa:

- Les va fatal en África -dijo.

Le pregunté si lo reconocían..., porque normalmente solo informaban de sus victorias.

- Escriben: "Nuestras tropas que luchan heroicamente". "Heroicamente” suena a necrología, créame.

Desde entonces, la palabra "heroicamente" sonó muchísimas veces a necrología en los partes de guerra y nunca nos engañó (Klemperer, 2018: 98).
} 
usó la palabra "guerra", más bien se optó por eufemismos o términos como "operaciones de limpieza", “incidentes", “jaleos", "campaña”, "alzamiento" o "disturbios" ("Donde España ha llevado la civilización y la paz, las hordas comunistas fomentan la subversión", La Vanguardia, 15-12-1957, p. 6).

La selección de palabras tampoco fue casual en los sucesos posteriores. Desde febrero de 1958, se produjo lo que el franquismo y la prensa española denominaron "la reorganización de territorios en la AOE" ("España permanecerá en Río de Oro y el Sáhara, afirma Pineau", $A B C$ (Sevilla), 13-4-1958, p. 31). Con ello, Ifni, o más bien Sidi Ifni, y el Sáhara español pasaron a ser provincias, con el mismo rango que Córdoba, Toledo o Ceuta. Sidi Ifni pasaba a estar dirigida por Gómez de Zamalloa como gobernador general. El objetivo de Franco era separar los espacios administrativamente para mantener Sáhara occidental en manos de España y entregar el resto a Marruecos. En abril de 1958, se entregaban Cabo Juby y Tarfaya al país magrebí, en los denominados Tratados de Cintra (Montoro, 1991: 188-189).

Pese a los cambios administrativos y sus repercusiones (López-Pozas Lanuza, 2018: 7884), los entrevistados coinciden en que, en los años sesenta, la vida entre la población civil se desarrollaba con normalidad, sin avisos de ataques ni atentados. En estos años, la prensa hacía hincapié en la construcción de viviendas e infraestructuras ("El nuevo barrio de Sidi Ifni", A.O.E. Revista ilustrada del África Occidental Española, 19-4-1964, pp. 36-37).

A pesar de esta aparente normalidad, Ruiz Gutiérrez afirma: "[En los sesenta] aunque no vivimos la guerra, [los soldados] pagamos sus consecuencias" (Luis Ruiz Gutiérrez en entrevista con la autora, Madrid, 2019). Aunque él fue asignado para la estafeta militar y la enseñanza de los hijos de oficiales, voluntariamente, pidió realizar una guardia nocturna: "En pleno desierto (...) hacíamos las guardias con cuatro bombas de mano en la cincha, que había que tirar en caso de peligro. (...) Teníamos una reserva de lo que había pasado antes, y de los moros no nos fiábamos" (Luis Ruiz Gutiérrez en entrevista con la autora, Madrid, 2019).

Nótese que la mayoría de entrevistados utiliza el término "moros" para designar a los habitantes de Ifni y Marruecos que eran musulmanes. La construcción de la imagen del "moro" es paralela a la evolución de las relaciones hispano-marroquíes. Se creó un discurso basado en una alteridad: identidad nacional versus "moro", expresión excluyente, peyorativa y reduccionista que se remonta a la época de la Reconquista, cuando el "moro" era identificado con el enemigo (Velasco de Castro, 2014: 206).

Pablo Vázquez Ramírez recuerda así la sociedad ifneña: “Era una ciudad pequeña en la que todos se conocían (...). En general se dividían en militares, civiles y nativos" (Pablo Vázquez Ramírez en entrevista digital con la autora, 2019). La separación social no 
impedía que hubiese una mezcla de culturas. Por ejemplo, hubo muchos "matrimonios mixtos" e hijos de estas uniones, como el actual alcalde de Ifni (Luis Ruiz Gutiérrez en entrevista con la autora, Madrid, 2019).

Al igual que la prensa, la mayoría de entrevistados sostiene que la población nativa y musulmana estaba contenta con la presencia española, y viceversa. Pese a ello, no podemos negar la realidad: "No solo en Ifni, en todo Marruecos desde 1957, los moros decían, porque no hablaban bien: "iViva la pendensia!», que quería decir "iViva la independencia!». [Aunque para algunos fue una sorpresa], (...) los europeos sabíamos que tarde o temprano nos íbamos a tener que ir de alli" (Luis Ruiz Gutiérrez en entrevista con la autora, Madrid, 2019).

Y así fue. En 1969, se produjo la denominada "retrocesión", un término político y jurídico que se podría traducir como "devolución de una cesión previa". La prensa española no hizo alusión al vocablo "pérdida" en ningún momento y, además, hizo hincapié en los territorios que todavía conservaba España: el actual Sáhara occidental, que fue provincia española hasta 1976. En este sentido, "retroceder", "transferir", "restituir", "traspasar" o "entregar" aparecen en numerosas ocasiones en los medios analizados como eufemismos de "perder" (Zuñiga, La Vanguardia, 24-4-1969, p. 15; "Entrega del patrimonio de Ifni”, La Vanguardia, 21-6-1969, p. 6; "España restituye a Marruecos el territorio de Ifni", $A B C$ (Madrid), 2-1-1969, p. 17).

Tras las reuniones de la ONU, en enero se anunció dicha "retrocesión", y en junio de ese año se efectuó. De acuerdo con la prensa, el tratado de retrocesión incluía un convenio pesquero que permitía a España seguir disfrutando de las riquezas pesqueras de las costas marroquíes ("Preparativos para las conversaciones hispano-marroquíes sobre la pesca en aguas de dicho país africano", La Vanguardia, 18-11-1969, p. 10), una cuestión que originaría disputas entre ambos países en los meses y años siguientes ("Desde la retrocesión de Ifni, doce embarcaciones españolas llevan capturadas los guardapescas marroquíes", $A B C$ (Madrid), 8-11-1969, p. 53).

En cualquier caso, la consecuencia para muchos españoles o descendientes de españoles, como los nacidos en matrimonios mixtos, fue su partida. Este fue el caso de María Teresa Suárez o la familia de Pablo Vázquez, que tuvo que vender a un escaso precio una panadería y un negocio mayor de comestibles que traían de Canarias.

Cuando esto sucedió, ni Luis Ruiz Gutiérrez ni Alfonso Carlos Alsúa estaban en el territorio, pero el acontecimiento pudo tener impacto a nivel psicológico: “(...) me sentí tristísimo, porque se repetía la historia. Para mí volvían a echarme de Marruecos [la primera en Tánger tras la independencia marroquí en 1956]. (...) Es como si de repente ponen un telón negro sobre tu vida y te dicen "Olvídate de aquello. Esta es tu realidad»" (Luis Ruiz Gutiérrez en entrevista con la autora, Madrid, 2019). 


\subsection{La culpabilización del comunismo}

Paralelamente a las tácticas informativas mencionadas, no se culpó a Marruecos ni mucho menos a Estados Unidos. Es más, se llegó a justificar la postura del país magrebí. Por tanto, encontramos dos estrategias análogas: la idea de hermanamiento hispanomarroquí y la culpabilización del comunismo (Pérez García, 2006: 179-196).

Esta estrategia formaba parte de una de las obsesiones de Franco, "la conspiración judeo-masónica-comunista" (Eiroa y Carrera, 2008: 80-81), a la que echó la culpa de los problemas de su gobierno. Como señala Vidal Guardiola: "Se quería hacer ver que los intereses soviéticos estaban presentes tanto en Marruecos, como en Argelia, Túnez, Egipto, Siria, etc." (Vidal Guardiola, 2006: 112).

De este modo, se establecía una supuesta relación entre el régimen soviético y los movimientos del norte africano. En los años cincuenta y sesenta, se incluyen numerosos ejemplos de esta idea en la prensa generalista ("Donde España ha llevado la civilización y la paz, las hordas comunistas fomentan la subversión", La Vanguardia, 15-12-1957, p. 6; "Responsabilidad y consecuencias", ABC (Madrid), 19-2-1958, p. 19).

En un contexto de Guerra Fría, en el que la URSS fomentaba la insurrección en países como Egipto, culpar al bloque soviético podía implicar recibir ayuda de Estados Unidos. Sin embargo, no fue así. Es más, Estados Unidos se acercó a Marruecos, que le procuraba un punto estratégico, como se comprobó en la reunión entre el presidente estadounidense, Eisenhower, y el rey marroquí, Mohamed V.

Es cierto que, aunque no se culpe al país vecino, se habla de la provisión de armas marroquíes al Ejército de Liberación. En última instancia, las guerrillas estaban apoyadas por el gobierno de Rabat y por el silencio administrativo de Estados Unidos (Vidal Guardiola, 2006: 91). Pese a ello, Franco no podía enfrentarse al país norteamericano, quien le había dado legitimidad internacional a partir de la firma de los acuerdos de 1953.

\subsection{La idea de hermanamiento con Marruecos y los argumentos de "legitimidad histórica"}

Desde el punto de vista internacional, el franquismo había apoyado al Marruecos de Mohamed $\mathrm{V}$, incluso contra el colonialismo francés, y había buscado alianzas con países sudamericanos y árabes, como Egipto o Siria, que le pudieran proporcionar materias primas, sobre todo durante el bloqueo internacional que vivió España entre 1945 y 1953. 
Franco probablemente se percató de que "su país amigo" estaba detrás del Ejército de Liberación, o que al menos lo apoyaba, pero no culpó a su aliado. La "demostración de fuerza de Agadir" que tuvo lugar el 7 de diciembre de 1957 arroja algo de luz: navíos de la flota española se posicionaron en el puerto de Agadir, en las costas marroquíes, amenazando con bombardear la ciudad, una advertencia a su aliado (Canales Torres y Rey Vicente, 2010: 113-144).

Pese a todo, la prensa siguió hablando de la buena amistad hispano-marroquí, tanto en los albores del conflicto ("Acusaciones marroquíes desmentidas en Madrid", $A B C$ (Madrid), 29-11-1957, p. 31) como posteriormente ("La retirada de la peseta en Marruecos y la unificación monetaria en aquel país", La Vanguardia, 26-04-1958, p. 4). En cualquier caso, se trataba de una estrategia, no solo mediática, sino también diplomática.

En su alianza con Marruecos, el franquismo recuperó tópicos decimonónicos que apelaban a una idealizada civilización andalusí (Velasco de Castro, 2014: 205-236). Con todo, aplicó un doble filo, pues gran parte de la población y muchos franquistas (el mismo Franco, Mola, Berenguer, etc.) defendían el racismo y la imagen del "moro" como un ser bárbaro e inferior, mientras que, por ejemplo, el propio Franco tenía la "guardia mora" a su servicio. Vestida de manera muy pomposa y residiendo cerca del Palacio del Pardo, la guardia mora desapareció cuando se dio la independencia a Marruecos en 1956. La proyección del "moro", así como del generalísimo o jefe de Estado (García Álvarez, 2010: 224), se observa en la filatelia de los cincuenta y sesenta que tan anunciada era en la prensa9 .

Justo en esta época, también influye el denominado "protectorado sentimental", concepto del político franquista Beigbeder: el colonialismo español buscaba diferenciarse de otros, como el francés, apelando al altruismo y al deber nacional e histórico de España en el norte africano, en favor del progreso y la civilización, cuestión reflejada en la prensa (Gómez Salomé, Ya, 21-12-1956, p. 3; Miró, Ya, 20-12-1956, p. 3). Por ello, se puede afirmar que se pasó “(...) de la «hermandad» a la tutela del hermano menor marroquí" (Velasco de Castro, 2014: 220), pues en el fondo su postura escondía relaciones que no se muestran como igualitarias.

Todo ello formaba parte del discurso de "los llamados cronistas áulicos del régimen" (Velasco de Castro, 2014: 217). Entre ellos, hallamos a García Figueras, que es una firma frecuente en los periódicos $A B C$ y $L a$ Vanguardia. Sus piezas son especialmente paradigmáticas, pues vemos en ellas las principales estrategias comunicativas, como la

\footnotetext{
9 Por ejemplo, es representativo que existiese, a la altura de 1959, un día dedicado al sello colonial ("La Exposición Juvenil del I Congreso Internacional de Filatelia de Barcelona”, La Vanguardia, 19-12-1959, p. 44).
} 
culpabilización del comunismo o argumentos de "legitimidad histórica" (García Figueras, La Vanguardia, 27-4-1960, p. 11; García Figueras, ABC (Sevilla), 1-10-1960, p. 7).

Estas últimas argumentaciones abarcan el Tratado de Wad-Ras, e incluso se remontan a Santa Cruz del Mar la Pequeña y la época de los Reyes Católicos. Se trata de cuestiones que también se recogen en los escritos de José Díaz de Villegas, ideólogo del régimen, publicados también en la prensa generalista (Díaz de Villegas, La Vanguardia, 23-3-1967, p. 16). Díaz de Villegas lideró la Dirección de Plazas y Provincias (1956-1968) ${ }^{10}$ y, como tal, tenía la capacidad de elegir a los gobernadores generales de AOE, África Occidental Española.

La idea de hermanamiento con Marruecos continuó incluso en la década de los sesenta, a pesar de que el gobierno de Rabat ya había reivindicado su legitimidad sobre Ifni y el Sáhara. Solo en estos años se cuestiona la postura de Marruecos y se le llega a culpar de estar detrás de los ataques del Ejército de Liberación ("La política de amistad leal y profunda hacia Marruecos no ha sido correspondida", La Vanguardia, 23-3-1961, p. 3).

\section{Conclusiones}

Ifni resulta ser una muestra muy representativa de los ingredientes que suelen darse, a nivel general, en la propaganda de guerra. En ella, los medios de comunicación, en este caso la prensa, juegan un papel de vital importancia. Las estrategias comunicativas analizadas en la prensa española son el reflejo de los mecanismos de control informativo por parte del franquismo.

En este caso, la propaganda consistió en hacer creer a la opinión pública que Marruecos era aliado y que, en Ifni, y en general en África Occidental Española, no pasaban asuntos serios.

Entre las reglas o técnicas de la propaganda política, y por extensión de la propaganda de guerra, encontramos las siguientes, en las que vemos una correlación con el caso examinado.

En primer lugar, se recurrió a la utilización del héroe o mártir, con constantes apelaciones al heroísmo y al patriotismo.

\footnotetext{
${ }^{10}$ La Dirección, que procedía de la dictadura de Primo de Rivera (1923-1930), en los años cuarenta, pasó, por decreto, a estar en manos de la Presidencia del Gobierno, o lo que es lo mismo: de Carrero Blanco (Suárez Blanco, 1997: 319).
} 
En segundo lugar, existió una exageración o minimización de la información, como se pone de manifiesto, por ejemplo, en el hecho de restar importancia a la guerra u ocultar las cifras de bajas y muertos.

En tercer lugar, hallamos la repetición, como mostramos en páginas anteriores.

En cuarto lugar, hallamos un sujeto grupal en el discurso franquista, como se observa en los términos ejército español o España, acorde con una ideología franquista castrense y un claro elogio al Ejército.

Por último, aunque no menos importante, encontramos la localización de un enemigo: el comunismo. El marxismo, y, en última instancia, el bloque soviético formaban un enemigo fantasma que en realidad no existía y que se usó, una vez más, como chivo expiatorio. A mi entender, si hubiera existido, ya se habría encargado Estados Unidos de intervenir en favor de España, y no fue así.

En cualquier caso, la Guerra de Ifni cayó en el olvido deliberadamente, fruto de la censura y del control que el régimen franquista ejercía sobre los medios de comunicación, hipótesis de la que partíamos.

Aunque, ciertamente, la prensa no borró del todo las huellas de la guerra, se basó en la elección de las palabras o la manipulación del lenguaje para disiparlas. Se trata de algo que, hoy en día, se podría calificar incluso de negacionismo. Los testigos entrevistados se erigen como las voces y ecos de aquella contienda y esa región que ya casi nadie conoce, y demuestran que, aunque no ha interesado, la guerra "olvidada e ignorada" podría dejar de serlo: frente al negacionismo y el olvido, la memoria y el rigor histórico.

Se puede concluir que el conflicto de Ifni fue una guerra defensiva que la prensa española, en primera y última instancia controlada por el régimen franquista, intentó mostrar como una hazaña vinculada a un ejército y un pasado gloriosos. Para Franco, habría sido una vergüenza contar que el Ejército español había sido arrinconado por unas supuestas guerrillas "bárbaras", que en realidad estaban muy bien estructuradas y apoyadas por agentes exteriores, principalmente Marruecos, algo que apenas se contó, o al menos solo se hizo de una manera oscura y ambigua.

Actualmente, las secuelas de la guerra no son solo visibles, también son estragos psicológicos. A pesar de que en 2007 el BOE establecía que el Ministerio de Defensa estudiaría los casos de estos combatientes para ofrecerles compensaciones, estas "ayudas nominales" todavía son una asignatura pendiente.

Tampoco hay un reconocimiento a los nativos de origen baamaraní que sirvieron al Ejército español, quienes entonces contaban con nacionalidad española, algunos ya fallecidos, ni tampoco a sus viudas ni descendientes. En el "Instrumento de ratificación 
del Tratado de Retrocesión de 1969", tan solo se les dio un plazo de tres meses para optar a la nacionalidad española. Este plazo imponía una imposibilidad en la práctica por inconvenientes como la falta de alfabetización, que hacía requerir un intermediario que tal vez los ifneños no podían pagar, por la diferencia de idiomas y/o el desembolso que suponía.

Muchos de ellos y sus sucesores todavía, hoy en día, siguen luchando por la obtención de la nacionalidad española. Por tanto, la falta de reconocimiento no solo afecta a brigadas, también a personas nativas, de origen mixto, baamaraní y/o musulmán, y a las mujeres olvidadas del territorio ifneño, como la entrevistada María Teresa Suárez Lorenzo, que entonces era una niña, o su madre, ya fallecida. Al fin y al cabo, los "héroes", es decir, las personas que vivieron el conflicto y que no aparecían tanto en la prensa, fueron también mujeres, niños y personas de origen baamaraní.

Ifni nos deja las imágenes de aquellos soldados con alpargatas, algunos sin ser conscientes de lo que realmente pasaba, otros creyendo que hacían algo heroico, intentando salvar los últimos bastiones de una España colonialista, cuando realmente eran utilizados por el régimen franquista y sus ansias regeneracionistas, que se remontaban al Desastre de 1898. En realidad, el colonialismo a la altura de los cincuenta del siglo XX era insostenible, sobre todo si se tiene en cuenta las nuevas corrientes descolonizadoras que surgieron tras la Segunda Guerra Mundial (1939-1945) y las presiones internacionales de la ONU, Marruecos y Estados Unidos.

En definitiva, este trabajo pone de manifiesto que la cobertura de la Guerra de Ifni ha sido un ejemplo más de manipulación informativa, una práctica que se ha ejercido a lo largo de toda la historia de la comunicación. Como posible línea futura de investigación, se podría ahondar aun más en dicha cuestión con un estudio comparativo entre la prensa nacional examinada y la prensa extranjera (por ejemplo, francesa, inglesa o marroquí).

En definitiva, está claro que hay una tergiversación de la memoria colectiva, sobre todo en relación con el franquismo. Es responsabilidad de todos, especialmente de los historiadores, pero también de las generaciones futuras, cuidar esta memoria, aunque, así mismo, hay que reconocer que el ocultamiento de la información también se puso de manifiesto tras el fin del franquismo y se extiende a todos los ámbitos de la sociedad, no solo a la esfera meramente política. 


\section{Referencias bibliográficas}

\section{Fuentes hemerográficas}

$A B C$ (Madrid). 1950-1969.

$A B C$ (Sevilla). 1950-1969.

A.O.E. Revista ilustrada del África Occidental Española. 1957-1965.

BÁRBULO, T. (2007): “Ifni, la guerra que perdió Franco" en El País, noviembre de 2007. Disponible en Internet (9-12-2019): https://elpais.com/diario/2007/11/18/eps/1195370811 850215.html.

Blanco y negro, suplemento de $A B C$. 1957-1969.

BOSQUE COMA, A. (2007) "La Guerra olvidada: último conflicto armado de España" en La aventura de la Historia, nำ119, 2007, pp. 38-44.

Informaciones. 1957.

La Vanguardia. 1953-1969.

No-do: noticiarios y documentales. 13 de enero de 1958.

Ya. 1956-1957.

\section{Fuentes orales}

ALSÚA, A.C. Comunicación telefónica. Octubre de 2019.

DALMASES Y OLABARRÍA, P.I. Comunicación personal y telefónica. Noviembre de 2019. RUIZ GUTIÉRREZ, L. Comunicación personal. Madrid. Octubre de 2019.

SUÁREZ LORENZO, M.T. Comunicación telefónica. Octubre de 2019.

VÁZQUEZ RAMÍREZ, P. Comunicación digital. Noviembre de 2019. 


\section{Bibliografía}

BOX, Z. (2004): "Secularizando el apocalipsis. Manufactura mítica y discurso nacional franquista: la narración de la victoria", en Historia y política: ideas, procesos y movimimentos sociales, no 12, pp. 161-186. Disponible en Internet (9-12-2019): http://www.cepc.gob.es/publicaciones/revistas/revistaselectronicas?IDR=9\&IDN $=641 \& \mid \mathrm{DA}=26748$.

CANALES TORRES, C. y REY VICENTE, M.D. (2010): “Capítulo 5: La recuperación en Ifni” en Oyarzábal, G.D. y Torres Vitolas, J.L. (editores), Breve historia de la guerra de Ifni-Sáhara. 1957. La última guerra española, Madrid, Nowtilus, pp. 113-144.

EIROA, M., y CARRERA, P. (2008): España voz en off. Teoría y praxis de la prensa española en el contexto de la Guerra Fría, Valencia, Tirant Lo Blanch.

GARCÍA ÁLVAREZ, L.B. (2010): "Las representaciones y la filatelia franquista”, en Historia Contemporánea, no 40. Disponible en Internet (9-12-2019): https://ojs.ehu.eus/index.php/HC/article/view/2149/1769.

GONZÁLEZ SÁEZ, J.M. (2014): “Ifni en el No-Do (1943-1969)” en Revista Internacional de Historia de la Comunicación, no 2, vol. 1, pp. 62-85. Disponible en Internet (9-122019): https://revistascientificas.us.es/index.php/RiHC/article/view/6167.

KLEMPERER, V. (2018): “X. Literatura autóctona” en Kovacsics, A. (traductor), La lengua del Tercer Reich: apuntes de un filólogo, Barcelona, Minúscula, pp. 97-101.

LÓPEZ-POZA LANUZA, J.C. (2018): "Repercusiones del conflicto hasta la retrocesión de Ifni" en Revista del Ejército de Tierra español, no 922, pp. 78-84. Disponible en Internet

(9-12-2019):

https://ejercito.defensa.gob.es/Galerias/multimedia/revistaejercito/2018/922//accesible/Revista Ejercito Accesible.pdf.

MADARIAGA, M.R. (2013): “1. El juego de las naciones ante la ofensiva colonial del siglo XIX" en Marruecos ese gran desconocido. Breve historia del protectorado español, Madrid, Alianza, pp. 23-69.

- (2013): “2. El Tratado de 1912, un «subarriendo» de Francia” en Marruecos ese gran desconocido. Breve historia del protectorado español, Madrid, Alianza, pp. 71-113.

MATESE, G. (2014): “Manipulación, persuasión e ideología franquista en el discruso político de prensa sobre el Sáhara Occidental", en Discurso \& Sociedad, no 4, vol. 8, pp. 623-666. Disponible en Internet (9-12-2019): http://www.dissoc.org/ediciones/v08n04/DS8\%284\%29Maltese.pdf. 
MOLINERO RUIZ, C. (2002): “"Crónica sentimental» y falsa memoria del franquismo”, en Historia del presente, no 1, pp. 98-100. Disponible en Internet (9-12-2019): https://dialnet.unirioja.es/servlet/articulo?codigo=1300192.

MONTORO, G. (1991): "La retrocesión de Tarfaya e Ifni”, en Espacio, Tiempo y Forma, no 4, pp. 181-189. Disponible en Internet (9-12-2019): http://revistas.uned.es/index.php/ETFV/article/view/2733/2593.

PÉREZ GARCÍA, G. (2003): "La falacia histórica sobre la colonia de Ifni" en Historia y comunicación social, no 8, pp. 207-222. Disponible en Internet (9-12-2019): https://core.ac.uk/download/pdf/38816259.pdf.

- (2006): "La guerra de Ifni y la falsa culpabilización al comunismo internacional por parte del régimen franquista" en Revista de estudios de comunicación = Komunikazio ikasketen aldizkaria, no 20, pp. 179-196. Disponible en Internet (912-2019): https://www.ehu.eus/ojs/index.php/Zer/article/view/3756.

PIZARROSO QUINTERO, Alejandro (1990): “Introducción al estudio de la propaganda” en Historia de la propaganda, Madrid, Eudema, pp. 25-41.

REIG CRUAÑES, J. (1995): “Comunicación política en el último franquismo" en Comunicación y Estudios Universitarios, no5, 1995, pp. 123-134.

SANTAMARÍA QUESADA, R. (1984): Ifni-Sáhara. La guerra ignorada, Madrid, Dyrsa.

SUÁREZ BLANCO, S. (1997): “Las colonias españolas en África durante el primer franquismo (1939-1959). Algunas reflexiones" en Espacio, Tiempo y Forma, no 10, pp. 315-331. Disponible en Internet (9-12-2019): http://revistas.uned.es/index.php/ETFV/article/view/2945/2805.

VELASCO DE CASTRO, R. (2014): "La imagen del moro en la formulación e instrumentalización del africanismo franquista" en Hispania, no 246, pp. 205-236. Disponible en Internet (9-12-2019): http://hispania.revistas.csic.es/index.php/hispania/article/view/425/421.

VIDAL GUARDIOLA, L.M. (2006): Ifni (1957-1958), la prensa y la guerra que nunca existió, Madrid, Almena. 


\section{Anexo}

En el siguiente apartado se incluye una selección de noticias como muestra de las noticias analizadas. Cada título está vinculado con el enlace para acceder directamente a aquella información que está digitalizada:

\begin{tabular}{|c|c|c|c|c|}
\hline Fecha & Autor & Titular & Cabecera & Resumen \\
\hline $\begin{array}{l}09- \\
08- \\
1958\end{array}$ & Redacción & $\begin{array}{l}\text { "Las primeras } \\
\text { noticias directas } \\
\text { de los españoles } \\
\text { desaparecidos } \\
\text { durante el ataque } \\
\text { de Ifni" }\end{array}$ & $\begin{array}{l}\text { La } \\
\text { Vanguardia }\end{array}$ & $\begin{array}{l}\text { Los desaparecidos en los } \\
\text { primeros ataques de Ifni (por } \\
\text { ejemplo, en el atentado del faro } \\
\text { de Cabo Bojador) están bien, } \\
\text { pero siguen bajo el control del } \\
\text { Ejército de Liberación. }\end{array}$ \\
\hline $\begin{array}{l}23- \\
03- \\
1961\end{array}$ & Redacción & $\begin{array}{l}\text { "La política de } \\
\text { amistad leal y } \\
\text { profunda hacia } \\
\text { Marruecos no ha } \\
\text { sido } \\
\text { correspondida" }\end{array}$ & $\begin{array}{l}\text { La } \\
\text { Vanguardia }\end{array}$ & $\begin{array}{l}\text { Marruecos reivindica su } \\
\text { soberanía sobre el Sáhara y } \\
\text { rechaza la política de alianza de } \\
\text { España, quien no dudará en } \\
\text { actuar ante cualquier acto de } \\
\text { violencia. }\end{array}$ \\
\hline $\begin{array}{l}21- \\
06- \\
1969\end{array}$ & Redacción & $\begin{array}{l}\text { "Entrega del } \\
\text { patrimonio de Ifni" }\end{array}$ & $\begin{array}{l}\text { La } \\
\text { Vanguardia }\end{array}$ & $\begin{array}{l}\text { Fraga anuncia la retrocesión de } \\
\text { Ifni a Marruecos para el } \\
\text { próximo } 30 \text { de junio por } \\
\text { decreto. }\end{array}$ \\
\hline $\begin{array}{l}06- \\
03- \\
1966\end{array}$ & $\begin{array}{l}\text { Ma del } \\
\text { Rosario } \\
\text { González- } \\
\text { Vegas }\end{array}$ & $\begin{array}{l}\text { "Sidi- Ifni ya tiene } \\
\text { puerto" }\end{array}$ & $A B C$ (Madrid) & $\begin{array}{l}\text { La inauguración del puerto de } \\
\text { Sidi Ifni tendrá lugar } \\
\text { próximamente (quizá en un } \\
\text { mes), que es descrito como un } \\
\text { triunfo de España frente al mar. } \\
\text { Era necesario un puerto por la } \\
\text { naturaleza de estas costas. }\end{array}$ \\
\hline $\begin{array}{l}05- \\
01- \\
1969\end{array}$ & Redacción & $\begin{array}{l}\text { "España cede Ifni a } \\
\text { la soberanía } \\
\text { marroquí" }\end{array}$ & $A B C$ (Madrid) & $\begin{array}{l}\text { Ya se ha formado en Fez un } \\
\text { tratado entre España y } \\
\text { Marruecos que incluye dos } \\
\text { importantes puntos: Ifni se } \\
\text { retrocede a Marruecos, y se } \\
\text { establece un pacto para la } \\
\text { pesca. }\end{array}$ \\
\hline $\begin{array}{l}03- \\
11- \\
1957\end{array}$ & Redacción & $\begin{array}{l}\text { "La vida en los } \\
\text { territorios de la } \\
\text { A.O.E." }\end{array}$ & $\begin{array}{l}\text { A.O.E. Revista } \\
\text { ilustrada del } \\
\text { África }\end{array}$ & $\begin{array}{l}\text { Se informa sobre aspectos } \\
\text { cotidianos de Ifni: educación, } \\
\text { misas, clima, subastas, } \\
\text { alquileres, etc. }\end{array}$ \\
\hline
\end{tabular}


Occidental

Española

\begin{tabular}{|c|c|c|c|c|}
\hline $\begin{array}{l}09- \\
02- \\
1958\end{array}$ & $\begin{array}{l}\text { Ramiro } \\
\text { Santamaría }\end{array}$ & $\begin{array}{l}\text { "Otro héroe } \\
\text { nacional en Ifni: } \\
\text { Enrique Carrasco" }\end{array}$ & $\begin{array}{l}\text { A.O.E. Revista } \\
\text { ilustrada del } \\
\text { África } \\
\text { Occidental } \\
\text { Española }\end{array}$ & $\begin{array}{l}\text { Se rinde homenaje a Enrique } \\
\text { Carrasco, teniente legionario } \\
\text { paracaidista, fallecido en Ifni en } \\
\text { pro de la victoria de España. }\end{array}$ \\
\hline $\begin{array}{l}20- \\
04- \\
1958\end{array}$ & Redacción & $\begin{array}{l}\text { "Adiós a la II } \\
\text { bandera de } \\
\text { paracaidistas" }\end{array}$ & $\begin{array}{l}\text { A.O.E. Revista } \\
\text { ilustrada del } \\
\text { África } \\
\text { Occidental } \\
\text { Española }\end{array}$ & $\begin{array}{l}\text { Se rinde homenaje a la II } \\
\text { Bandera de Paracaidistas, } \\
\text { liderada por Ortiz de Zárate, } \\
\text { resaltando su acción heroica en } \\
\text { Ifni. }\end{array}$ \\
\hline $\begin{array}{l}27- \\
11- \\
1957\end{array}$ & Redacción & $\begin{array}{l}\text { "Nota del } \\
\text { Ministerio del } \\
\text { Ejército" }\end{array}$ & $Y a$ & $\begin{array}{l}\text { El Ejército de Liberación ha } \\
\text { atacado los territorios de Ifni } \\
\text { por sorpresa, pero el ejército } \\
\text { español ha actuado con éxito. }\end{array}$ \\
\hline $\begin{array}{l}28- \\
11- \\
1957\end{array}$ & Redacción & $\begin{array}{l}\text { "Sin novedad en } \\
\text { las zonas próximas } \\
\text { a Sidi Ifni" }\end{array}$ & $Y a$ & $\begin{array}{l}\text { No hay novedades en Ifni, de } \\
\text { modo que son falsas las } \\
\text { informaciones transmitidas por } \\
\text { algunos medios extranjeros. }\end{array}$ \\
\hline $\begin{array}{l}29- \\
11- \\
1957\end{array}$ & Redacción & $\begin{array}{l}\text { "El Jefe de Estado } \\
\text { felicita a las } \\
\text { fuerzas de Ifni" }\end{array}$ & $Y a$ & $\begin{array}{l}\text { El jefe de Estado felicita a las } \\
\text { tropas españolas de Ifni. La } \\
\text { ofensiva militar española } \\
\text { prosigue de manera favorable y } \\
\text { se desmiente que las } \\
\text { estrategias militares españolas } \\
\text { se hayan dirigido a personas } \\
\text { procedentes de Ifni o del Sáhara } \\
\text { español. }\end{array}$ \\
\hline $\begin{array}{l}27- \\
11- \\
1957\end{array}$ & Redacción & $\begin{array}{l}\text { "Nota del } \\
\text { Ministerio del } \\
\text { Ejército" }\end{array}$ & Informaciones & $\begin{array}{l}\text { El Ejército de Liberación ha } \\
\text { atacado los territorios de Ifni } \\
\text { por sorpresa, pero el ejército } \\
\text { español ha actuado con éxito. }\end{array}$ \\
\hline $\begin{array}{l}28- \\
11- \\
1957\end{array}$ & Redacción & $\begin{array}{l}\text { "La situación en las } \\
\text { zonas próximas a } \\
\text { Sidi Ifni" }\end{array}$ & Informaciones & $\begin{array}{l}\text { No hay novedades en Ifni, son } \\
\text { falsas las informaciones } \\
\text { transmitidas por algunos } \\
\text { medios extranjeros. }\end{array}$ \\
\hline $\begin{array}{l}29- \\
11- \\
1957\end{array}$ & Redacción & $\begin{array}{l}\text { "Sidi Ifni, } \\
\text { asegurado contra } \\
\text { todo ataque" }\end{array}$ & Informaciones & $\begin{array}{l}\text { El Jefe de Estado felicita a las } \\
\text { tropas españolas de Ifni. La } \\
\text { ofensiva militar española } \\
\text { prosigue de manera favorable y } \\
\text { se desmiente que las }\end{array}$ \\
\hline
\end{tabular}


estrategias militares españolas se hayan dirigido a personas

procedentes de Ifni o del Sáhara.

Tabla 2. Muestra de la metodología empleada. Fuente: elaboración propia. 